\title{
Clinical Study \\ Enhanced Inflammatory Activity of Endometriotic Lesions from the Rectovaginal Septum
}

\author{
Dominic Bertschi, ${ }^{1}$ Brett D. McKinnon, ${ }^{1,2}$ Jakob Evers, ${ }^{1}$ \\ Nick A. Bersinger, ${ }^{1,2}$ and Michael D. Mueller ${ }^{1}$ \\ ${ }^{1}$ Department of Obstetrics and Gynecology, Inselspital, Berne University Hospital, 3010 Berne, Switzerland \\ ${ }^{2}$ Department of Clinical Research, University of Berne, 3010 Berne, Switzerland
}

Correspondence should be addressed to Brett D. McKinnon; brett.mckinnon@dkf.unibe.ch

Received 9 August 2013; Accepted 22 November 2013

Academic Editor: Charles J. Malemud

Copyright (C) 2013 Dominic Bertschi et al. This is an open access article distributed under the Creative Commons Attribution License, which permits unrestricted use, distribution, and reproduction in any medium, provided the original work is properly cited.

\begin{abstract}
Endometriosis is characterised by the growth of ectopic lesions at multiple locations outside the uterine cavity and may be considered a collection of distinct but related conditions. The exact aetiology of endometriosis is still not clear although a role for inflammation is increasingly accepted. We therefore investigated the inflammatory activity of eutopic tissue and that of the matching ectopic lesions from different locations by measuring the genetic expression of inflammatory chemokines and cytokines. The gene expression in matching eutopic and ectopic tissue was compared, as was the gene expression in lesions from different locations. A significantly higher mRNA expression of the chemokines ENA-78 and RANTES and the cytokines IL-6 and TNF $\alpha$ was observed in endometriotic lesions of the rectovaginal septum (RVS) compared to that of matching eutopic tissue. Comparisons across lesion locations showed a significantly higher expression of IL-6 and TNF $\alpha$ in the RVS compared to lesions from either the ovaries or the peritoneum. These results show that the production of some inflammatory chemokines and cytokines is significantly increased in the ectopic endometrial tissue compared to matching eutopic tissue. Furthermore, IL-6 and TNF $\alpha$ are produced in significantly higher quantities in RVS lesions compared to other lesions.
\end{abstract}

\section{Introduction}

Endometriosis is defined as the presence of endometrial tissue outside the uterine cavity. The most common symptoms leading to a diagnosis are dysmenorrhoea, pelvic pain, and reduced fertility [1]. It is a very prevalent disease affecting up to $10 \%$ of the reproductive-aged female population [2].

The precise aetiology of endometriosis is not yet clear. Currently, the most widely accepted theory is the implantation theory: retrograde menstruation can result in viable endometrial cells and fragments entering the peritoneal cavity [3] and once attached [4], they promote a chronic pelvic inflammatory response [5]. Retrograde menstruation however cannot explain all cases, as endometriotic lesions have been identified in diverse locations such as the brain [6]. It is broadly accepted however that most of the ectopic lesions can be separated into three main regions: (i) ovarian, (ii) rectovaginal septum (RVS), and (iii) peritoneum. Biochemical and pathological differences between the lesions found in these locations have led to suggestions that endometriosis may represent a collection of related but distinct conditions [7]. It is possible that the variability between these distinct but related lesions is what contributes to the enigmatic nature of the disease.

The contribution of inflammation to the progression of endometriosis is increasingly being recognised. Endometriotics lesions that are established at ectopic sites secrete chemokines which attract macrophages into the peritoneal cavity, further stimulating the inflammatory response and release of cytokines [8]. Significantly increased numbers of activated macrophages have been identified in the peritoneal fluid of women with endometriosis [9], as has an increased concentration of various chemokines and cytokines. Significantly elevated levels of epithelial neutrophil-activating 
peptide (ENA-78) [10], monocyte chemotactic protein (MCP1) [11], interleukin (IL)-8 [12], tumor necrosis factor (TNF)- $\alpha$ [13], IL-6 $[14,15]$, and regulated on activation normal T cell expressed and secreted (RANTES) [12] have all been found in the peritoneal fluid of patients with endometriosis. Underlining the inflammatory nature of the condition is the fact that TNF $\alpha$ [16], ENA-78 [17], and IL-6 [18, 19] are also elevated in the serum of women with endometriosis. Less data is however available on the inflammatory response of the lesion itself and whether there is variability based on the type or lesion location. A difference in the production of specific cytokines may provide an insight into the inflammatory activity of lesions that grow in different locations.

In order to gain a better understanding of this complex disease and the differences that can occur between various lesions, this study investigated the production of several chemokines and cytokines in matching eutopic endometrial and ectopic endometriotic tissue and compared their gene expression levels in the three most common presentations of the disease.

\section{Patients and Methods}

2.1. Sample Collection and Patient Data. Informed consent was collected prior to surgery from all women included in the study. Laparoscopic surgery was performed for the investigation of pelvic pain or infertility, and any endometriotic lesions identified were removed and their location was noted. Where possible, an endometrial biopsy was also collected using a soft curette (Pipelle-de-cornier, Laboratoire CCD, France). All tissue collected during the surgery was stored in RNAlater (Invitrogen Life Technologies, Zug, Switzerland) at $-80^{\circ} \mathrm{C}$ until further use. Exclusion criteria for the study included prior or current infections, liver dysfunction, or the use of hormonal treatments, including any hormonal contraceptive or gonadotropin releasing hormone analogues (GnRHa) within the past 3 months. All laparoscopies were performed in the proliferative phase of the menstrual cycle. Institutional review board approval was obtained from the ethical committee prior to the commencement of the study.

After the informed consent was obtained and exclusion criteria were satisfied, we collected eutopic endometrial biopsies from 17 patients. A single matching ectopic lesion was collected from 15 women, two lesions were collected from another, and three lesions in the final case, resulting in 20 ectopic lesions with matching eutopic samples. The primary indication for surgery was dysmenorrhea for ten of these women, pelvic pain for four women, and infertility for the remaining three. The average age of the patients was $32.94 \pm 1.454$, range $24-41$, and the body mass index (BMI) was $23.39 \pm 0.914$, range 18.90-33.10.

For the further comparison of the mRNA expression across ectopic sites additional lesions were collected from another 23 patients to make a total of 40 patients. A single lesion was collected from 34 patients, two lesions were collected from five patients, and three lesions were collected from one patient, resulting in a total of 47 ectopic endometriotic lesions. In some cases the isolated mRNA was insufficient to determine the concentration of all genes of interest and as such $n$ values are included with each mean and SEM. The primary indication for surgery was dysmenorrhea for 17 women, pelvic pain for another 14, and idiopathic infertility for the remaining nine. The average age was $35.58 \pm$ 1.265 , range $22-58$, and the BMI was $23.79 \pm 0.811$, range 18.00-47.30. No significant difference in either age or BMI was observed in the three groups based on lesion location.

\subsection{Determination of Gene Expression in Eutopic Endome-} trium and Ectopic Endometriotic Tissue. Approximately $30 \mathrm{mg}$ of tissue from both the eutopic endometrial biopsies and ectopic endometriotic lesions was excised and homogenized in the FastPrep 120 tissue homogenizer (30 seconds at $4.0 \mathrm{~m} / \mathrm{sec}$ ) in cell lysis buffer (Qiagen, Düsseldorf, Germany). RNA isolation was performed with the RNAeasy minikit (Qiagen) and after isolation the TurboDNase kit (Ambion, Life Technologies, Zug, Switzerland) was used for genomic DNase digestion. One microgram of the total RNA was reverse transcribed in a $25 \mu \mathrm{L}$ reaction volume with the Moloney murine leukemia virus (MMLV) reverse transcriptase (Promega, Dübendorf, Switzerland) and random primers. The resulting cDNA was diluted 1:20 and the absence of genomic DNA was confirmed with a reverse transcriptase control.

The quantitative real time polymerase chain reaction (qPCR) was performed with the SYBR green Fast Advance Master Mix (Qiagen) and a Rotor-Gene RG 2000 (Corbett Research, NSW, Australia), under the following conditions, $95^{\circ} \mathrm{C}$ for $5 \mathrm{~min}$, followed by 40 cycles of $95^{\circ} \mathrm{C}$ for 5 second, and $60^{\circ} \mathrm{C}$ for 10 seconds. Specificity of the reaction was confirmed via melt curve analysis and the product size was confirmed on a $4 \%$ agarose gel.

The Genbank accession number and the primer sequences for all genes examined by qPCR are shown in Table 1.

2.3. Statistical Analysis. The most stable reference genes and the optimal combination to provide minimal variability were selected via the geNORM software program and a geometric mean of the four reference genes selected was used to normalise the expression of the genes of interest for both the eutopic and ectopic tissue [20]. The reaction efficiency of each assay was determined via linear regression [21] and the fold change calculated with the qBASEplus software (Biogazelle, Zwijnaarde, Belgium).

The difference between the matched eutopic and ectopic mRNA expression at different locations and the difference between mRNA in different ectopic locations were determined by a one-way Analysis of Variance (ANOVA) test with a post hoc Bonferroni's multiple comparisons test between selected groups. All values are presented as mean \pm SEM and all statistical analysis was performed with Graphpad Prism 5.0 and significance was set at a value of $P<0.05$.

\section{Results}

3.1. Cytokine mRNA Concentrations in Matching Eutopic and Ectopic Endometrial Tissue. For the chemokines a oneway ANOVA test confirmed a significant variation between 
TABle 1: Primer sequences of the reference genes and genes of interest.

\begin{tabular}{|c|c|c|c|}
\hline Cytokine & $\begin{array}{c}\text { Genbank accession } \\
\text { no. }\end{array}$ & Sense & Antisense \\
\hline GAPDH & NM_002046 & $5^{\prime}-T G C$ ACC ACC AAC TGC TTA GC- $3^{\prime}$ & $5^{\prime}$-GGC ATG GAC TGT GGT CAT GAG-3' \\
\hline АСТВ & NM_001101 & $5^{\prime}-C T G$ GAA CGG TGA AGG GTG ACA-3' & $5^{\prime}-A A G G G A C T T$ CCT GTA ACA ATG CA-3' \\
\hline YWHAZ & NM_003406 & $5^{\prime}-$ ACT TTT GGT ACA TTG TGG CTT CAA - $3^{\prime}$ & 5'-CGC CAG GAC AAA CCA GTA T-3' \\
\hline RPL13A & NM_012423 & $5^{\prime} C C T$ GGA GGA GAA GAG GAA AGA-3' & $5^{\prime}-T T G$ AGG ACC TCT GTG TAT TTG TCA A-3' \\
\hline IL-6 & NM_00600 & $5^{\prime}$-GCA CTG GCA GAA AAC AAC CT-3' & $5^{\prime}$-CAG GGG TGG TTA TTG CAT CT-3' \\
\hline IL-8 & NM_000584 & $5^{\prime}$ - ACT GAG AGT GAT TGA GAG TGG AC-3' & $5^{\prime}-A A C$ CCT CTG CAC CCA GTT TTC - $3^{\prime}$ \\
\hline ENA-78 & NM_02994 & 5'-CTC CAA TCT TCG CTC CTC CAA-3' & $5^{\prime}-G G A$ GGC TCA TAG TGG TCA AGA G-3' \\
\hline $\mathrm{TNF} \alpha$ & NM_000594 & $5^{\prime}-G C C$ CAT GTT GTA GCA AAC CC-3' & $5^{\prime}$-TAT CTC TCA GCT CCA CGC CA-3' \\
\hline MCP-1 & NM_002982 & $5^{\prime}-G G G$ CAT TGA TTG CAT CTG GC-3' & $5^{\prime}-C T G$ CTC ATA GCA GCC ACC TT-3' \\
\hline PAPP-A & NM_002581 & $5^{\prime}$-AGT GGT ATC CTC ACC CTG CT-3' & $5^{\prime}$-GTT GCA AAA GGC TCG GTT GT-3' \\
\hline RANTES & NM_002985 & $5^{\prime}-C T G$ CTT TGC CTA TGC CC-3' & $5^{\prime}-T C G$ GGT GAC AAA GAC GAC TG-3' \\
\hline
\end{tabular}

the mRNA concentrations of the ectopic endometriotic tissue with eutopic endometrial tissue for ENA-78 $(P=0.0039)$ and RANTES $(P=0.0490)$, but not for MCP-1 $(P=0.1251)$ or IL-8 $(P=0.7991)$ (Figure 1). A Bonferroni's multiple comparisons test was performed to compare the mean of each location against the eutopic mean. No significant difference was observed for MCP-1 mRNA expression between the eutopic tissue $(0.107 \pm 0.015, n=17)$ and the ovarian lesions $(2.751 \pm 1.943, n=8, P<0.05)$, the peritoneal $(0.590 \pm 0.167$, $n=7, P<0.01)$ or the RVS $(1.865 \pm 0.712, n=4, P<0.01)$ lesions (Figure 1(a)). For ENA-78 there was a significantly stronger expression in the RVS lesions (5.905 $\pm 3.569, n=4$, $P<0.01)$ compared to the eutopic tissue $(0.613 \pm 0.250$, $n=17)$, but no difference was observed in lesions from either the ovaries $(0.811 \pm 0.290, n=8)$, or the peritoneum (1.444 \pm $0.504, n=7$ ) (Figure 1(b)). For IL-8 there was no significant variation in the mRNA expression in either the peritoneum $(0.396 \pm 0.114, n=8)$, the ovarian $(0.409 \pm 0.084, n=8)$, or the RVS (1.574 $\pm 0.385, n=5)$ compared to the eutopic tissue (3.979 $\pm 3.337, n=20$ ) (Figure 1(c)). A significantly higher expression of RANTES mRNA was observed in the RVS $(0.582 \pm 0.264, n=5, P<0.05)$ compared to the eutopic tissue $(0.239 \pm 0.0432, n=17)$, but not in either the peritoneum $(0.220 \pm 0.030, n=5)$ or the ovarian tissue $(0.190 \pm 0.045, n=8)$ (Figure 1(d)).

For the inflammatory cytokines a one-way ANOVA test confirmed a significant variation between the mRNA concentrations in the eutopic tissue with the mRNA concentration in the ectopic tissue for TNF $\alpha(P=0.0014)$ and IL-6 $(P<0.0001)$ (Figure 2). A post hoc Bonferroni's multiple comparisons test indicated that TNF $\alpha$ mRNA expression in both the peritoneal $(1.939 \pm 0.667, n=8, P<0.05)$ and the RVS $(3.128 \pm 1.608, n=4, P<0.01)$ samples was significantly higher than that observed for their matching eutopic tissue $(0.444 \pm 0.106, n=17)$, although no difference was observed with the ovarian lesions $(0.291 \pm 0.034, n=8)$ (Figure 2(a)). For IL-6 there was a significantly higher expression in the RVS region $(9.308 \pm 3.714, n=5, P<0.0001)$, but not the ovaries $(0.689 \pm 0.237, n=7)$ or the peritoneal region $(0.667 \pm 0.237$, $n=7)$ compared to the eutopic tissue $(0.152 \pm 0.091, n=17)$ (Figure 2(b)).

3.2. Cytokine mRNA Concentrations of Ectopic Endometriotic Lesions from Different Locations. A significant variation was observed between the mRNA expression of TNF $\alpha(P=$ $0.0265)$ and IL-6 $(P<0.0001)$, amongst the endometriotic lesions from different locations. A post-hoc Bonferroni's multiple comparisons test indicated that the TNF $\alpha$ mRNA expression in the RVS $(2.590 \pm 1.357, n=5)$ was significantly higher than in the ovarian lesions $(0.813 \pm 0.144, n=24$, $P<0.05)$, but not in the peritoneal lesions $(1.711 \pm 0.460$, $n=12)$. For IL- 6 the mRNA expression in the RVS lesions $(10.150 \pm 3.148, n=6)$ was significantly higher than the expression in both the ovaries $(1.260 \pm 0.323, n=24, P<$ $0.0001)$ and the peritoneum $(1.211 \pm 0.400, n=13, P<$ 0.0001) (Figure 3).

In contrast no significant difference in mRNA expression was observed for any of the four chemokines examined in this study. MCP-1 expression in the RVS $(1.700 \pm 0.576, n=5)$ was not significantly higher than either the ovarian $(1.393 \pm 0.632$, $n=25)$ or the peritoneal samples $(0.814 \pm 0.215, n=13)$, which was also the case for ENA-78 (Peritoneal; $1.497 \pm 0.465$, $n=13$, ovarian; $2.988 \pm 1.429, n=25$, RVS; $4.822 \pm 2.969, n=$ 5), IL-8 (peritoneum; $1.548 \pm 1.188, n=13$, ovaries; $1.352 \pm$ $0.471, n=25$, RVS; $2.017 \pm 0.543, n=6$ ), and RANTES (peritoneal; $0.288 \pm 0.064, n=11$, ovarian; $0.364 \pm 0.054$, $n=22$, RVS; $0.528 \pm 0.222, n=6$ ) (Figure 3 ).

\section{Discussion}

The study showed that the mRNA expression of the chemokines ENA-78 and RANTES, as well as the inflammatory cytokines TNF $\alpha$ and IL-6, was significantly increased in the ectopic lesion compared to those in the matched eutopic tissue in women with endometriosis. For IL-6, ENA-78, and RANTES this increase was most significant in the RVS region, whereas for $\mathrm{TNF} \alpha$, it was in both the peritoneal lesions and the RVS lesions. In addition, when compared across lesion 


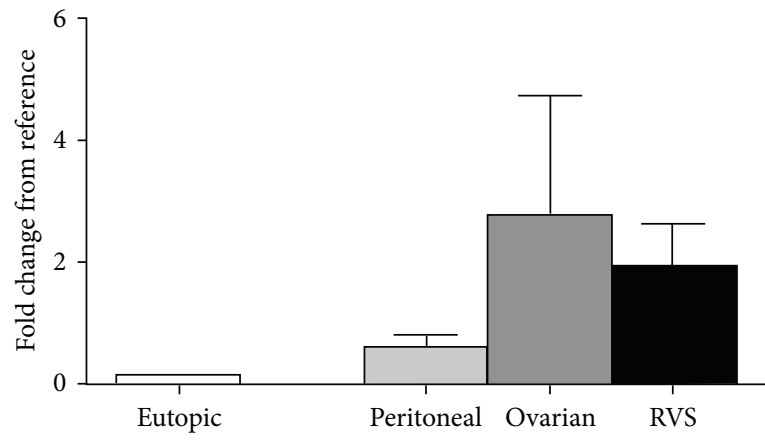

(a)

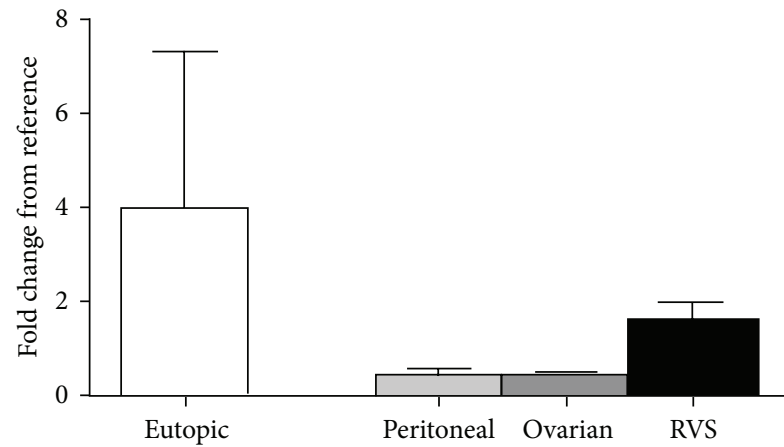

(c)

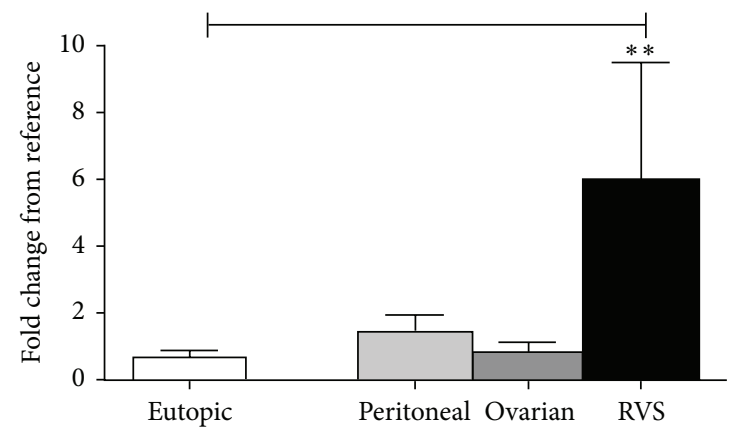

(b)

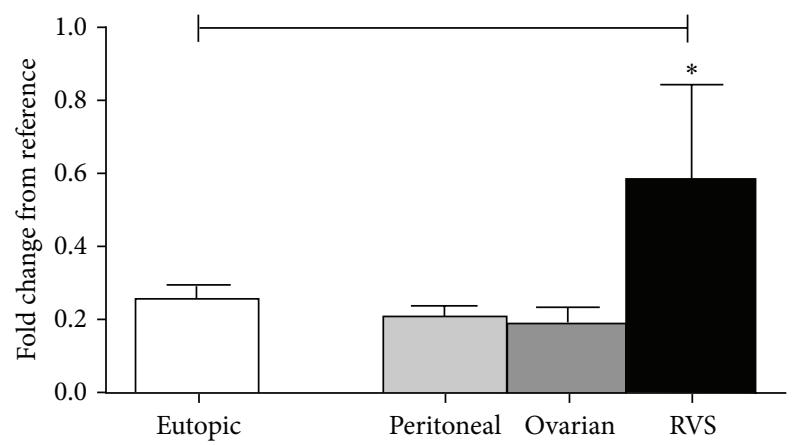

(d)

Figure 1: Chemokine production in eutopic endometrium and matching ectopic endometriotic lesions from different locations. (a) No significant difference was observed in the mRNA expression of MCP-1. (b) ENA-78 mRNA expression was significantly stronger in the RVS lesions compared to its matching eutopic tissue. (c) No significant difference in IL-8 mRNA expression was observed between the eutopic endometrium and the ectopic lesions from different locations. (d) RANTES expression was significantly higher in the RVS lesions compared to the eutopic endometrium. All values are represented by mean \pm SEM. ${ }^{*}<.05,{ }^{* *}<.01$.

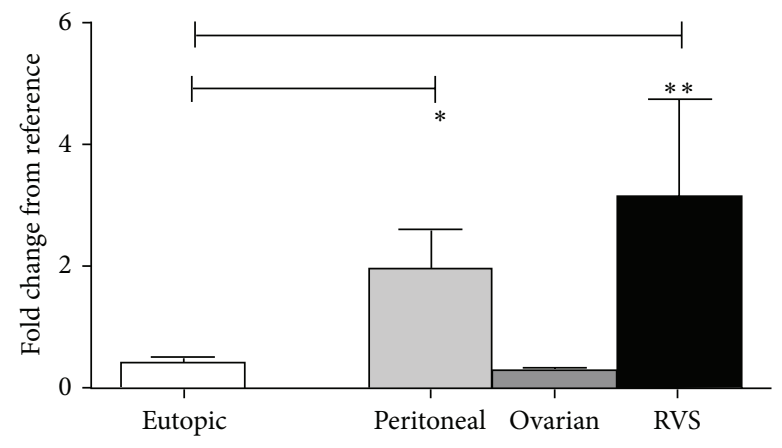

(a)

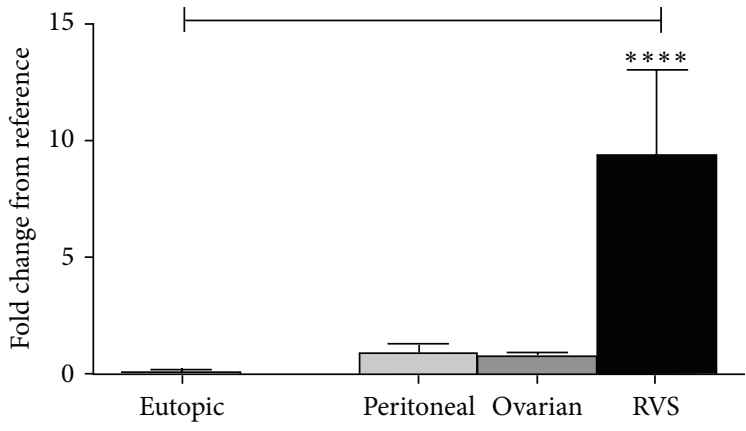

(b)

FIGURE 2: Inflammatory cytokine mRNA expression in eutopic and matching ectopic endometriotic lesions from different locations. (a) The mRNA expression of TNF $\alpha$ was significantly higher in the peritoneal and RVS lesions compared to their matching eutopic endometrium. (b) The mRNA expression of IL- 6 was significantly higher only in the RVS lesions. All values are represented by mean \pm SEM. ${ }^{*}<.05,{ }^{* *}<.01$, ${ }^{* * * *}<.0001$.

locations IL-6 was the most highly expressed in the RVS region compared to either the ovaries or the peritoneum. The results suggest therefore that different inflammatory proteins have separate roles in different lesions and understanding these roles may help to specifically target certain presentations of endometriosis. In addition, the increased production of many of these proteins by the RVS lesions provides some molecular evidence towards the notion that lesions developing in the RVS are strongly inflammatory.

Increased expression of chemokines by ectopic endometrial implants is an important early stage in the pathogenesis of endometriosis. Chemokines secreted by the ectopic lesions stimulate the infiltration of macrophages that further contribute to the development of the disease. In this 


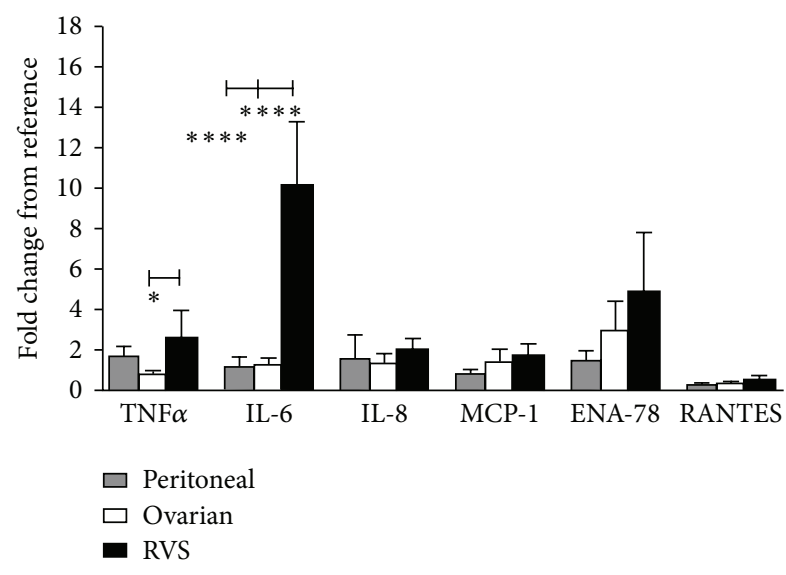

FIgURE 3: Comparison of cytokine and chemokine concentrations in endometriotic lesions from different locations. A comparison of the mRNA expression between endometriotic lesions from different locations indicated that TNF $\alpha$ expression in the RVS was significantly higher than expression in the ovarian lesions. IL-6 mRNA expression was significantly higher in the RVS than either the ovarian or the peritoneal lesions. There was no significant difference between the lesions with any of the other cytokines. All values are represented by mean \pm SEM. ${ }^{*}<.05,{ }^{* * * *}<.0001$.

study we found a significant increase in the expression of RANTES and ENA-78 in the RVS lesions compared to the matching eutopic tissue. RANTES production by ectopic lesions recruits leukocytes [22], which then in turn stimulates RANTES production [23] creating a feedback loop. Previous studies support this result as RANTES correlates with deep infiltrating endometriosis (DIE), which is most commonly found in the RVS [24]. ENA-78 may also play a significant role in the pathogenesis of endometriosis via the activation of macrophages and the adhesion of endometriotic cells to the underlying tissue [25]. Previous studies have shown that both endometrial epithelial [26] and stromal cells [27] produce significant amounts of ENA-78, which is stimulated by IL$1 \beta$, although this is the first evidence to indicate a significant upregulation in production of ENA-78 by RVS lesions.

IL-8 has strong chemotactic properties for neutrophils and $\mathrm{T}$ lymphocytes and is a potent angiogenic agent [28]. While numerous studies have shown an upregulation of IL-8 in the peritoneal fluid of women with endometriosis $[29,30]$ the source is not clear. An increase in peritoneal macrophages may be responsible for a higher concentration of IL-8, as would an increased production of IL-8 by the endometriotic lesions themselves.. Previous evidence shows that both cultured epithelial and stromal endometrial and endometriotic cells produce IL-8 [26, 27], although one study found that the ectopic tissue produced less IL-8 than the eutopic tissue [31]. Another study on cultured epithelial and stromal cells showed that IL-8 secretion is increased after exposure to IL-1 $\beta$ [26]. The lack of a significant difference for IL-8 in this study may be a reflection of the need to stimulate IL-8 production in endometriotic tissue.

TNF $\alpha$ mRNA expression was also significantly up-regulated in both the RVS and the peritoneal lesions compared to those in their matching eutopic tissue. For IL-6 a significant variation was only observed in the RVS lesion. TNF $\alpha$ has an essential role in the inflammatory process. The primary function of TNF $\alpha$ is to initiate a cascade of other cytokines that can further stimulate a proinflammatory response. In endometriosis it correlates with both the stage of the disease [32], and the menstrual pain reported [33]. Consistent with its early role in the inflammatory cycle it also stimulates cytokines, such as IL-6. The increased expression of TNF $\alpha$ is consistent with an important role for this cytokine in the early pathogenesis of endometriosis that may be common for different types of lesions. The fact that IL- 6 is only significantly higher in RVS lesions may suggest that the inflammatory pathway between these two lesions may diverge prior to this point.

IL-6 is a multifunctional cytokine that can stimulate cell proliferation [34] and angiogenesis [35] and is hormonally regulated [36]. Different studies have shown both an increase $[14,15]$ or no change in the peritoneal fluid of women with endometriosis compared to women without [37]. IL-6 production has previously been identified in ectopic lesions, however results differ as to whether there is a change in production once the tissue becomes pathological. Some studies have found no significant difference between eutopic endometrium and endometriotic tissue from ovarian endometriosis [31], whereas others with ovarian endometriosis only [38], or non-detailed locations, have shown significant increases [39]. Furthermore, an in vitro study from endometrial stromal cells isolated from chocolate ovarian cysts showed a significant ability to produce IL- 6 with production comparable to that of peritoneal macrophages [40]. None of these previous studies however have addressed the production of IL-6 in lesions from different locations.

A limitation of this study that should be mentioned is the small number of samples available for the RVS region. This is primarily due to the strict exclusion criteria for this study. As evidence indicates that the use of GnRHa can have an effect on the cytokine concentrations in the peritoneal fluid [41,42] we excluded all samples from women with previous $\mathrm{GnRHa}$ use in the last 3 months. As women with RVS lesions are more likely to experience painful symptoms and to have previously sought treatment for endometriosis, a large proportion of women presenting to our tertiary care facility with RVS lesions had previous GnRHa or contraceptive use and thus were excluded from the study. However, although we only had a small number of samples, the ability to use matched eutopic and ectopic samples and our strict exclusion criteria should provide more weight to these results. Further studies with more samples should be performed to confirm our findings of differential cytokine production from lesions from different locations.

In conclusion, this study gives new insights in the production of chemokines and cytokines in endometriotic lesions from different locations and our results support the supposition that the RVS lesions are an intensely inflammatory form of endometriotic lesions. Assessing lesions from different locations uniquely may be vital in understanding the pathological changes of the disease and potentially for their mode of treatment. 


\section{Conflict of Interests}

None of the authors have a conflict of interests.

\section{References}

[1] N. Sinaii, K. Plumb, L. Cotton et al., "Differences in characteristics among 1,000 women with endometriosis based on extent of disease," Fertility and Sterility, vol. 89, no. 3, pp. 538-545, 2008.

[2] B. Eskenazi and M. L. Warner, "Epidemiology of endometriosis," Obstetrics and Gynecology Clinics of North America, vol. 24, no. 2, pp. 235-258, 1997.

[3] J. A. Sampson, "Metastatic or embolic endometriosis, due to the menstrual dissemination of endometrial tissue into the venous circulation," The American Journal of Pathology, vol. 3, no. 2, pp. 93-110. 43, 1927.

[4] C. A. Witz, "Cell adhesion molecules and endometriosis," Seminars in Reproductive Medicine, vol. 21, no. 2, pp. 173-181, 2003.

[5] R. O. Burney and L. C. Giudice, "Pathogenesis and pathophysiology of endometriosis," Fertility and Sterility, vol. 98, no. 3, pp. 511-519, 2012.

[6] L. L. Thibodeau, G. R. Prioleau, and E. E. Manuelidis, "Cerebral endometriosis. Case report," Journal of Neurosurgery, vol. 66, no. 4, pp. 609-610, 1987.

[7] M. Nisolle and J. Donnez, "Peritoneal endometriosis, ovarian endometriosis, and adenomyotic nodules of the rectovaginal septum are three different entities," Fertility and Sterility, vol. 68, no. 4, pp. 585-596, 1997.

[8] D. I. Lebovic, M. D. Mueller, and R. N. Taylor, "Immunobiology of endometriosis," Fertility and Sterility, vol. 75, no. 1, pp. 1-10, 2001.

[9] J. Halme, S. Becker, and M. G. Hammond, "Increased activation of pelvic macrophages in infertile women with mild endometriosis," American Journal of Obstetrics and Gynecology, vol. 145, no. 3, pp. 333-337, 1983.

[10] M. D. Mueller, L. Mazzucchelli, C. Buri, D. I. Lebovic, E. Dreher, and R. N. Taylor, "Epithelial neutrophil-activating peptide 78 concentrations are elevated in the peritoneal fluid of women with endometriosis," Fertility and Sterility, vol. 79, supplement 1, pp. 815-820, 2003.

[11] N. A. Bersinger, H. Dechaud, B. McKinnon, and M. D. Mueller, "Analysis of cytokines in the peritoneal fluid of endometriosis patients as a function of the menstrual cycle stage using the BioPlex platform," Archives of Physiology and Biochemistry, vol. 118, no. 4, pp. 210-218, 2012.

[12] N. A. Bersinger, S. von Roten, D. M. Wunder, L. Raio, E. Dreher, and M. D. Mueller, "PAPP-A and osteoprotegerin, together with interleukin- 8 and RANTES, are elevated in the peritoneal fluid of women with endometriosis," American Journal of Obstetrics and Gynecology, vol. 195, no. 1, pp. 103-108, 2006.

[13] M. A. Bedaiwy, S. A. El-Nashar, R. K. Sharma, and T. Falcone, "Effect of ovarian involvement on peritoneal fluid cytokine concentrations in endometriosis patients," Reproductive BioMedicine Online, vol. 14, no. 5, pp. 620-625, 2007.

[14] T. Harada, H. Yoshioka, S. Yoshida et al., "Increased interleukin6 levels in peritoneal fluid of infertile patients with active endometriosis," American Journal of Obstetrics and Gynecology, vol. 176, no. 3, pp. 593-597, 1997.

[15] I. Velasco, P. Acién, A. Campos, M. I. Acién, and E. Ruiz-Maciá, "Interleukin-6 and other soluble factors in peritoneal fluid and endometriomas and their relation to pain and aromatase expression," Journal of Reproductive Immunology, vol. 84, no. 2, pp. 199-205, 2010.

[16] S. Galo, P. Žúbor, N. Szunyogh et al., “TNF- $\alpha$ serum levels in women with endometriosis: prospective clinical study," Ceska Gynekologie, vol. 70, no. 4, pp. 286-290, 2005.

[17] Z. Cai, Y. He, and D. Peng, "Changes of serum epithelial neutrophil-activating peptide-78 in patients with endometriosis," Di Yi Jun Yi Da Xue Xue Bao, vol. 25, no. 4, pp. 464-465, 2005.

[18] M. A. Bedaiwy, T. Falcone, R. K. Sharma et al., "Prediction of endometriosis with serum and peritoneal fluid markers: a prospective controlled trial," Human Reproduction, vol. 17, no. 2, pp. 426-431, 2002.

[19] A. Mihalyi, O. Gevaert, C. M. Kyama et al., "Non-invasive diagnosis of endometriosis based on a combined analysis of six plasma biomarkers," Human Reproduction, vol. 25, no. 3, pp. 654-664, 2010.

[20] J. Vandesompele, K. De Preter, F. Pattyn et al., "Accurate normalization of real-time quantitative RT-PCR data by geometric averaging of multiple internal control genes," Genome Biology, vol. 3, no. 7, Article ID RESEARCH0034, 2002.

[21] J. M. Ruijter, C. Ramakers, W. M. H. Hoogaars et al., "Amplification efficiency: linking baseline and bias in the analysis of quantitative PCR data," Nucleic Acids Research, vol. 37, no. 6, article e45, 2009.

[22] D. Hornung, I. P. Ryan, V. A. Chao, J. Vigne, E. D. Schriock, and R. N. Taylor, "Immunolocalization and regulation of the chemokine RANTES in human endometrial and endometriosis tissues and cells," Journal of Clinical Endocrinology and Metabolism, vol. 82, no. 5, pp. 1621-1628, 1997.

[23] D. I. Lebovic, V. A. Chao, and R. N. Taylor, "Peritoneal macrophages induce RANTES (regulated on activation, normal T cell expressed and secreted) chemokine gene transcription in endometrial stromal cells," Journal of Clinical Endocrinology and Metabolism, vol. 89, no. 3, pp. 1397-1401, 2004.

[24] Y. Yang, X. Zhang, C. Zhou, X. Huang, J. Lin, and H. Xu, "Elevated immunoreactivity of RANTES and CCR1 correlate with the severity of stages and dysmenorrhea in women with deep infiltrating endometriosis," Acta Histochemica, vol. 115, no. 5, pp. 434-439, 2013.

[25] M. Nishida, K. Nasu, and H. Narahara, "Role of chemokines in the pathogenesis of endometriosis," Frontiers in Bioscience, vol. 3, pp. 1196-1204, 2011.

[26] N. A. Bersinger, F. Frischknecht, R. N. Taylor, and M. D. Mueller, "Basal and cytokine-stimulated production of epithelial neutrophil activating peptide-78 (ENA-78) and interleukin-8 (IL8 ) by cultured human endometrial epithelial and stromal cells," Fertility and Sterility, vol. 89, supplement, no. 5, pp. 1530-1536, 2008.

[27] N. A. Bersinger, A. R. Günthert, B. McKinnon, S. Johann, and M. D. Mueller, "Dose-response effect of interleukin (IL)-1 $\beta$, tumour necrosis factor (TNF)- $\alpha$, and interferon- $\gamma$ on the in vitro production of epithelial neutrophil activating peptide-78 (ENA-78), IL-8, and IL-6 by human endometrial stromal cells," Archives of Gynecology and Obstetrics, vol. 283, no. 6, pp. 12911296, 2011.

[28] A. Arici, "Local cytokines in endometrial tissue: the role of interleukin-8 in the pathogenesis of endometriosis," Annals of the New York Academy of Sciences, vol. 955, pp. 101-109, 118, 396406, 2002. 
[29] I. P. Ryan, J. F. Tseng, E. D. Schriock, O. Khorram, D. V. Landers, and R. N. Taylor, "Interleukin-8 concentrations are elevated in peritoneal fluid of women with endometriosis," Fertility and Sterility, vol. 63, no. 4, pp. 929-932, 1995.

[30] A. Arici, S. I. Tazuke, E. Attar, H. J. Kliman, and D. L. Olive, "Interleukin-8 concentration in peritoneal fluid of patients with endometriosis and modulation of interleukin-8 expression in human mesothelial cells," Molecular Human Reproduction, vol. 2, no. 1, pp. 40-45, 1996.

[31] A. Bergqvist, H. Nejaty, B. Fröysa et al., "Production of interleukins $1 \beta, 6$ and 8 and tumor necrosis factor alpha in separated and cultured endometrial and endometriotic stromal and epithelial cells," Gynecologic and Obstetric Investigation, vol. 50, no. 1, pp. 1-6, 2000.

[32] J. Eisermann, M. J. Gast, J. Pineda, R. R. Odem, and J. L. Collins, "Tumor necrosis factor in peritoneal fluid of women undergoing laparoscopic surgery," Fertility and Sterility, vol. 50, no. 4, pp. 573-579, 1988.

[33] B. Scholl, N. A. Bersinger, A. Kuhn, and M. D. Mueller, "Correlation between symptoms of pain and peritoneal fluid inflammatory cytokine concentrations in endometriosis," Gynecological Endocrinology, vol. 25, no. 11, pp. 701-706, 2009.

[34] S. Miki, M. Iwano, Y. Miki et al., "Interleukin-6 (IL-6) functions as an in vitro autocrine growth factor in renal cell carcinoma," FEBS Letters, vol. 250, no. 2, pp. 607-610, 1989.

[35] B. Motro, A. Itin, L. Sachs, and E. Keshet, "Pattern of interleukin 6 gene expression in vivo suggests a role for this cytokine in angiogenesis," Proceedings of the National Academy of Sciences of the United States of America, vol. 87, no. 8, pp. 3092-3096, 1990.

[36] A. Akoum, A. Lemay, I. Paradis, N. Rheault, and R. Maheux, "Secretion of interleukin- 6 by human endometriotic cells and regulation by proinflammatory cytokines and sex steroids," Human Reproduction, vol. 11, no. 10, pp. 2269-2275, 1996.

[37] A. Rapkin, M. Morgan, C. Bonpane, and O. Martinez-Maza, "Peritoneal fluid interleukin-6 in women with chronic pelvic pain," Fertility and Sterility, vol. 74, no. 2, pp. 325-328, 2000.

[38] A. Bergqvist, C. Bruse, M. Carlberg, and K. Carlström, "Interleukin $1 \beta$, interleukin- 6 , and tumor necrosis factor- $\alpha$ in endometriotic tissue and in endometrium," Fertility and Sterility, vol. 75, no. 3, pp. 489-495, 2001.

[39] A. Salmassi, Y. Acil, A. G. Schmutzler, K. Koch, W. Jonat, and L. Mettler, "Differential interleukin-6 messenger ribonucleic acid expression and its distribution pattern in eutopic and ectopic endometrium," Fertility and Sterility, vol. 89, supplement, no. 5, pp. 1578-1584, 2008.

[40] T. Tsudo, T. Harada, T. Iwabe et al., "Altered gene expression and secretion of interleukin-6 in stromal cells derived from endometriotic tissues," Fertility and Sterility, vol. 73, no. 2, pp. 205-211, 2000.

[41] W. Küpker, A. Schultze-Mosgau, and K. Diedrich, "Paracrine changes in the peritoneal environment of women with endometriosis," Human Reproduction Update, vol. 4, no. 5, pp. 719-723, 1998.

[42] K. Nirgianakis, N. A. Bersinger, B. McKinnon, P. Kostov, S. Imboden, and M. D. Mueller, "Regression of the inflammatory microenvironment of the peritoneal cavity in women with endometriosis by GnRHa treatment," European Journal of Obstetrics \& Gynecology and Reproductive Biology, vol. 170, no. 2, pp. 550-554, 2013. 


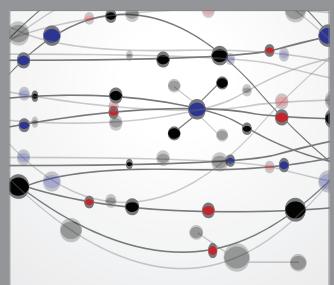

The Scientific World Journal
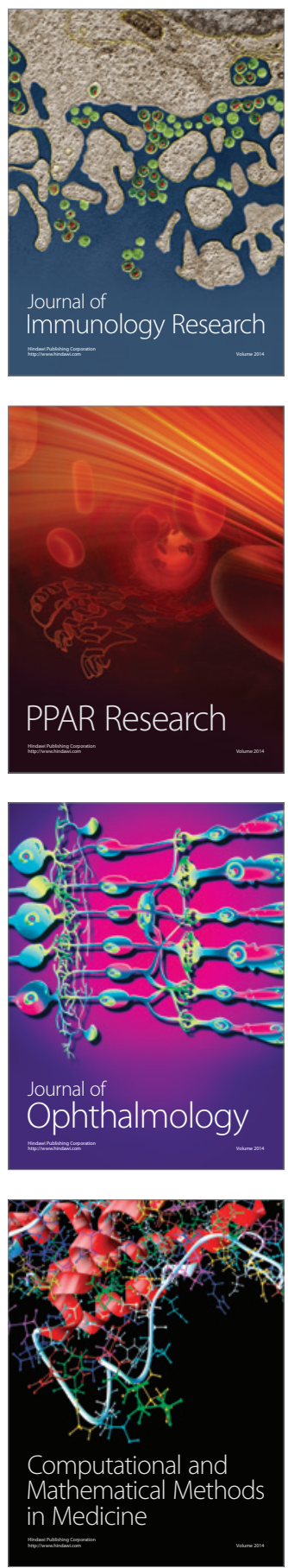

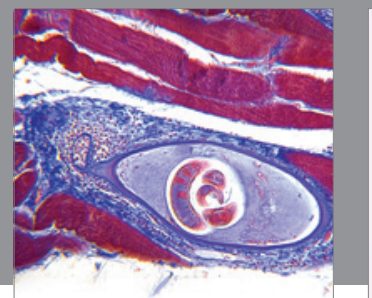

Gastroenterology

Research and Practice
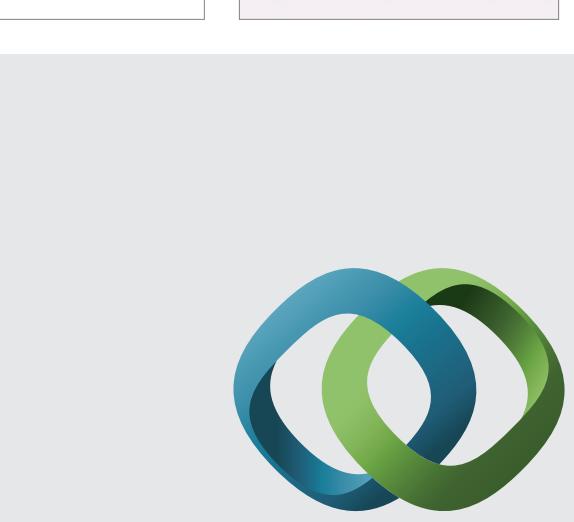

\section{Hindawi}

Submit your manuscripts at

http://www.hindawi.com
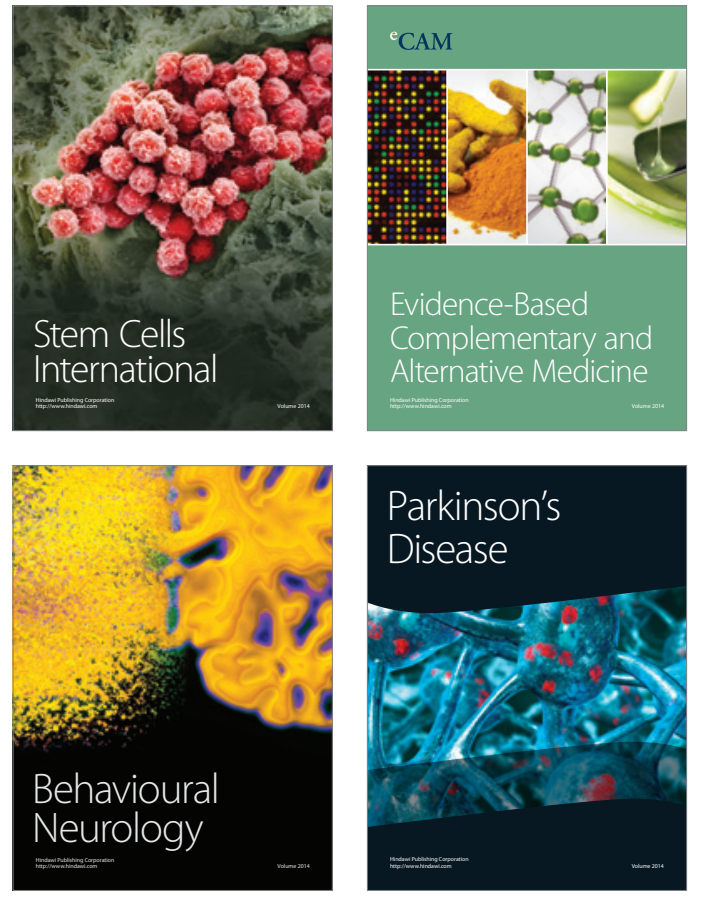
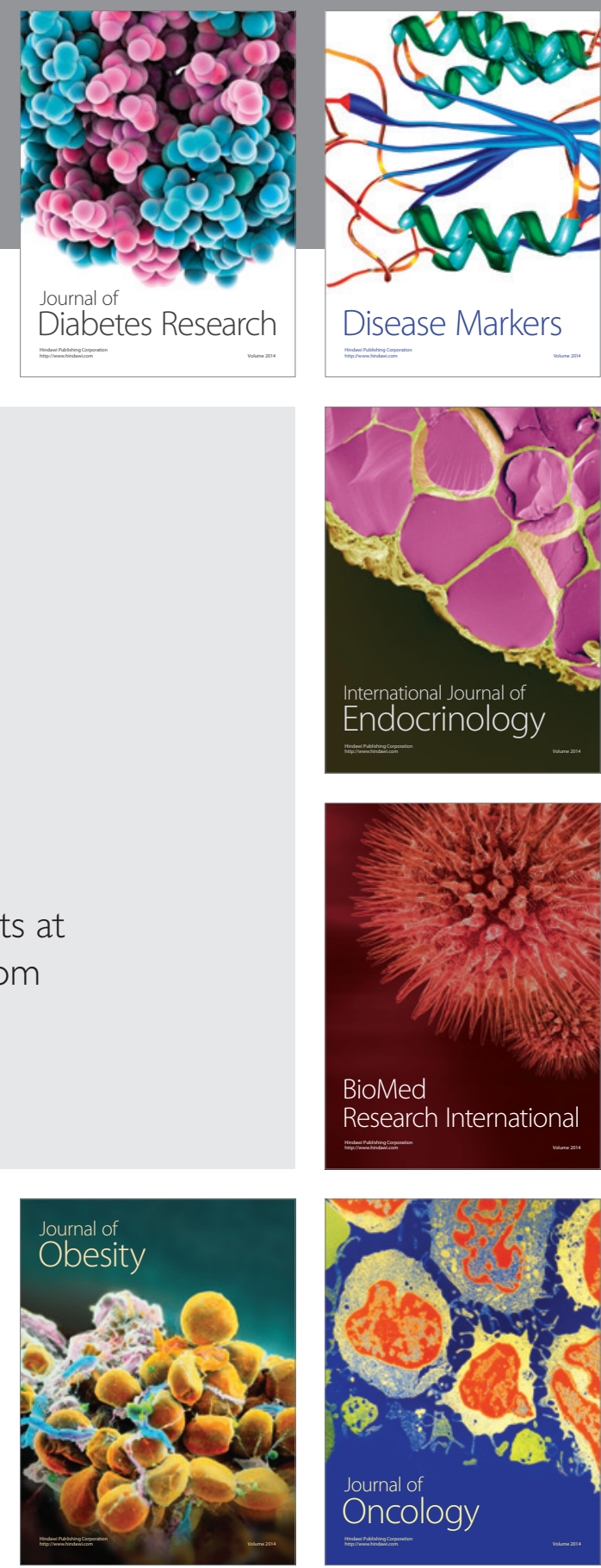

Disease Markers
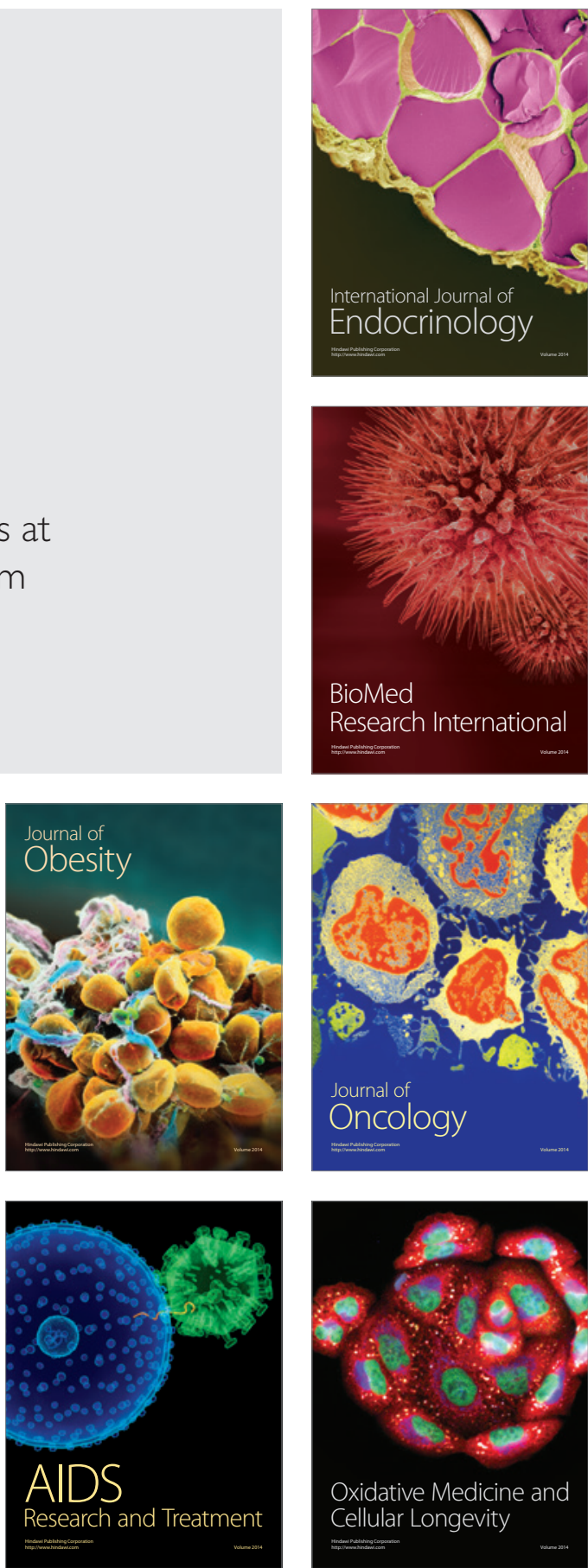